\title{
Use of the Thermal Chemical Vapor Deposition to Fabricate Light-Emitting Diodes Based on ZnO Nanowire/p-GaN Heterojunction
}

\author{
Sheng-Po Chang and Ting-Hao Chang \\ Institute of Microelectronics and Department of Electrical Engineering, Center for Micro/Nano Science and Technology, \\ Advanced Optoelectronic Technology Center, National Cheng Kung University, Tainan 70101, Taiwan \\ Correspondence should be addressed to Sheng-Po Chang, changsp@mail.ncku.edu.tw
}

Received 15 June 2011; Revised 4 August 2011; Accepted 11 August 2011

Academic Editor: Renzhi Ma

Copyright (C 2011 S.-P. Chang and T.-H. Chang. This is an open access article distributed under the Creative Commons Attribution License, which permits unrestricted use, distribution, and reproduction in any medium, provided the original work is properly cited.

\begin{abstract}
The fabrication and characteristics of grown $\mathrm{ZnO}$ nanowire/p-GaN heterojunction light-emitting diodes are reported. Vertically aligned $\mathrm{ZnO}$ nanowire arrays were grown on a $\mathrm{p}-\mathrm{GaN}$ substrate by thermal chemical vapor deposition in quartz tube. The rectifying current-voltage characteristics indicate that a $\mathrm{p}-\mathrm{n}$ junction was formed with a heterostructure of n- $\mathrm{ZnO}$ nanowire/p$\mathrm{GaN}$. The room temperature electroluminescent emission peak at $425 \mathrm{~nm}$ was attributed to the band offset at the interface between the $\mathrm{n}-\mathrm{ZnO}$ nanowire and $\mathrm{p}-\mathrm{GaN}$ and to defect-related emission from $\mathrm{GaN}$; it was also found that the there exist the yellow band in the hetrojunction. It would be attributed to the deep defect level in the heterojunction.
\end{abstract}

\section{Introduction}

Recently, nanowire- (NW-) based light-emitting diodes (LEDs) have become the focus of many researches and have also drawn considerable attention owing to their many advantages over conventional thin-film-based devices. NWs can improve light extraction without the use of a reflector because they can act as direct waveguides, and their nanostructure can overcome lower carrier injection efficiency because of a large band offset at the heterojunction interface. The nanojunction can also increase the contact area and aspect ratio and, hence, enhance carrier injection efficiency and recombination. Zinc oxide $(\mathrm{ZnO})$ has a wide bandgap $\left(E_{g}=3.37 \mathrm{eV}\right)$ and a stronger excitation binding energy $(60 \mathrm{meV})$ than gallium nitride $(\mathrm{GaN})(\sim 29 \mathrm{meV})$ [1]. In addition, $\mathrm{ZnO}$ is a natural n-type semiconductor and has a wurtzite structure $[2,3]$. These properties make $\mathrm{ZnO}$ a potential material to be used for ultraviolet (UV) photodetectors and other optoelectronic applications [4]. Moreover, $\mathrm{ZnO}$-based one-dimensional (1D) materials are widely used because of their high surface-area-to-volume ratio. Therefore, a large contact area of the $\mathrm{p}-\mathrm{n}$ junction structure could be fabricated to produce many kinds of optoelectronic devices such as LEDs and detectors. However, $\mathrm{ZnO}$ homojunction devices are difficult to fabricate because p-type doping in $\mathrm{ZnO}$ is not stable or reliable enough. Therefore, a heterojunction of $\mathrm{ZnO}$ and another material is needed to realize a $\mathrm{p}-\mathrm{n}$ junction, which is an important part of many devices. Heterojunction devices fabricated in previous studies utilized semiconductors such as $\mathrm{Cu}_{2} \mathrm{O}, \mathrm{Si}$, $\mathrm{SiC}$, and $\mathrm{GaN}[5-8]$.

Although several studies have investigated the use of $\mathrm{p}$ type $\mathrm{ZnO}$ to realize homojunction devices, the fabrication of such devices is difficult because p-type $\mathrm{ZnO}$ is not stable or reliable enough. $\mathrm{GaN}$ is a wide-bandgap semiconductor $\left(E_{g}=3.39 \mathrm{eV}\right)$ and has similar physical properties to $\mathrm{ZnO}$, including a small in-plane lattice mismatch $(\sim 1.8 \%)$ and the same wurtzite structure $[9,10]$. Therefore, $\mathrm{n}-\mathrm{ZnO} \mathrm{NW}$ based LEDs can be realized through a GaN heterojunction structure. Recently, many researchers have grown $\mathrm{ZnO}$ NWs using various techniques, including metal organic chemical vapor deposition (MOCVD), and electrodeposition. LED performance is not satisfactory with MOCVD [11-13]. Lupan et al. fabricated low-voltage UV LEDs with 
an electroluminescence (EL) emission wavelength at $397 \mathrm{~nm}$ at an applied voltage of $4.2 \mathrm{~V}$ [11]. However, these methods of growing NWs are complex and expensive. In this study, $\mathrm{ZnO} \mathrm{NW}$ hetrojunction was grown with a simple method by thermal chemical vapor deposition in quartz tube, because this method has many advantages such as process simply and short growth time, lower cost than MOCVD, and mass manufactures. The physical and electroptical properties of the fabricated LEDs are discussed.

\section{Experiment}

A p-GaN epitaxial film was deposited on a c-plane (0001) sapphire substrate by MOCVD; the sapphire substrate was purchased commercially. The ZnO NWs used in this study were grown on the $\mathrm{p}-\mathrm{GaN}$ substrate by thermal chemical vapor deposition. Zinc powder (99\%, Strem Chemicals) was used as a zinc vapor source. The zinc powder and substrates were inserted into a quartz tube using an alumina boat. Constant streams of argon gas at a rate of 54.4 SCCM (standard cubic centimeters per minute at STP) and oxygen gas at a rate of 0.8 SCCM were then introduced into the reaction system. The evaporation process was carried out for $30 \mathrm{~min}$ after the reaction system had reached a reaction temperature of $550^{\circ} \mathrm{C}$. A mechanical pump was utilized to maintain a reactive pressure of 10 Torr. Finally, a novel lightemitting diode was fabricated and packaged by the following method. A 3\% $\mathrm{HCl}$ aqueous solution was used to etch out the $\mathrm{n}-\mathrm{ZnO} \mathrm{NW}$ to expose the $\mathrm{p}-\mathrm{GaN}$ layer for a p-electrode. $\mathrm{Ni} / \mathrm{Au}(15 / 120 \mathrm{~nm})$ ohmic contacts were deposited on the p-GaN layer by thermal evaporation. Figure 1 shows the device processing steps used in this study. The fabricated sample was reversed and placed on the prepared ITO/glass substrate. The tips of the $\mathrm{ZnO}$ NWs contacted the ITO/glass substrate and formed a $\mathrm{ZnO} \mathrm{NW} / \mathrm{p}-\mathrm{GaN}$ structure to be used for the LED. In order to achieve good ohmic contact between the $\mathrm{ZnO}$ nanowires and ITO, the LED was placed into a thermal furnace and annealed at $200^{\circ} \mathrm{C}$ for $10 \mathrm{~min}$. The size distribution of the NWs and surface morphologies of the samples were elucidated using a JEOL JSM-7000F field emission scanning electron microscope (FE-SEM) operated at $10 \mathrm{KeV}$. The photoluminescence (PL) spectrum of the sample was measured at room temperature using a 325-nm HeCd laser, which acted as the excitation source.

\section{Results and Discussion}

Figure 2(a) shows a top-view FE-SEM image of as-grown ZnO NWs on GaN film. The SEM measurement shows that the $\mathrm{ZnO}$ NWs grow vertically and are connected to the GaN film. The $\mathrm{ZnO} \mathrm{NWs}$ are $1 \mu \mathrm{m}$ and $50-100 \mathrm{~nm}$ in diameter. Figure 2(b) presents an X-ray diffraction (XRD) pattern of $\mathrm{ZnO} \mathrm{NWs}$ on a $\mathrm{p}-\mathrm{GaN}$ substrate. In this figure, we can observe three clear peaks. The $\mathrm{ZnO}$ (0002) diffraction peak is to the left of the GaN (0002) peak, and the sapphire substrate (0006) exhibits a peak at $41.9^{\circ}$. This measurement shows that the $\mathrm{ZnO} \mathrm{NWs}$ are oriented with the $c$-axis, perpendicular to the GaN film. The $\mathrm{ZnO}$ and GaN peaks of the XRD pattern

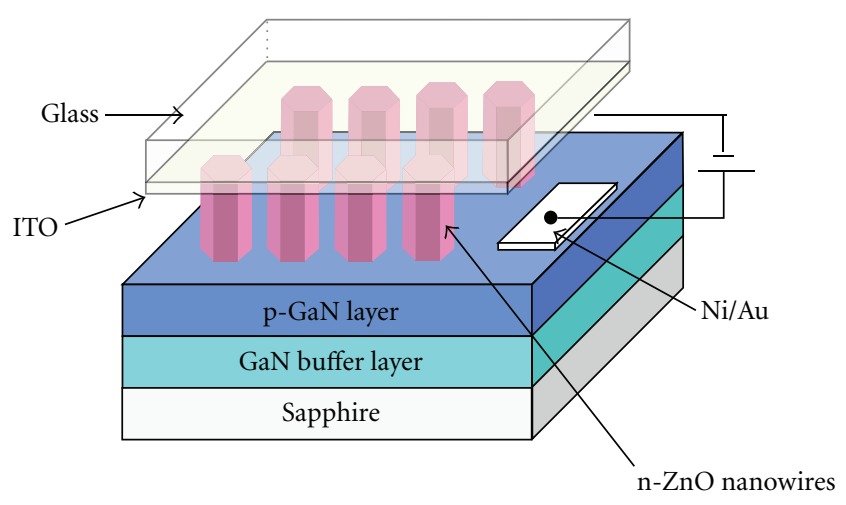

FIGURE 1: Structure of fabricated $\mathrm{n}-\mathrm{ZnO}$ nanowire/p-GaN heterojunction LED.

are located close to each other at $34.2^{\circ}$ and $34.8^{\circ}$, respectively, indicating that the strain existing between $\mathrm{GaN}$ and $\mathrm{ZnO}$ is very weak. The full width at half maximum (FWHM) values of $\mathrm{GaN}$ and $\mathrm{ZnO}$ are similar and sharp, indicating that the GaN film and ZnO NWs are of high quality. No other peak is observed, indicating that the preferred orientation of the NWs from the p-GaN film is achieved. Figure 2(c) shows an XRD rocking curve obtained for our sample. The extremely narrow FWHM observed from the rocking curve peak indicates that the $\mathrm{ZnO}$ nanowires prepared on the $\mathrm{p}$ GaN substrate in this study are indeed single crystalline with high crystal quality.

Figure 3 presents the PL spectrum of the $\mathrm{ZnO}$ NWs and $\mathrm{p}-\mathrm{GaN}$ film at room temperature. The $\mathrm{PL}$ spectrum of the $\mathrm{p}-\mathrm{GaN}$ film consists of two broad bands, centered at maximum wavelengths $(\lambda \mathrm{m})$ of 432 and $583 \mathrm{~nm}$. The broadband emission corresponds to a typical transition from the conduction band or shallow donors to the $\mathrm{Mg}$ acceptors. The PL spectrum of the $\mathrm{ZnO}$ NWs reveals a strong UV emission with a $\lambda \mathrm{m}$ of $379 \mathrm{~nm}$ and a FWHM of $16 \mathrm{~nm}$, because of near-band edge emission by $\mathrm{ZnO}$ with a wide bandgap.

In Figure 4, the current-voltage characteristics of the fabricated diode are plotted for bias voltages ranging from -5 to $10 \mathrm{~V}$. This figure illustrates that the large turn-on voltage was approximately $5.5 \mathrm{~V}$, which indicates that the thermal chemical vapor deposition procedure may produce a higher density of defects at the interface. From Figure 5, it is found that the EL emission rapidly increased with the applied forward bias, and the peak wavelengths were $425 \mathrm{~nm}$, $425 \mathrm{~nm}$, and $426 \mathrm{~nm}$ at $10 \mathrm{~V}, 15 \mathrm{~V}$, and $20 \mathrm{~V}$, respectively. The EL peak wavelength that is red shifted relative to the $\mathrm{PL}$ emission of $\mathrm{ZnO}$ is approximately $46 \mathrm{~nm}$, which could be attributed to the recombination of electrons and holes in $\mathrm{ZnO}$, causing an unexpected defect to occur in $\mathrm{ZnO}$ or at the interface between $\mathrm{ZnO}$ and GaN. Moreover, it is also found that there exists the yellow band in the hetrojunction; it is attributed to the deep defect level in the hetrojunction. The insert of Figure 5 shows the blue emission imaged with a CCD camera. The blue light radiating from 


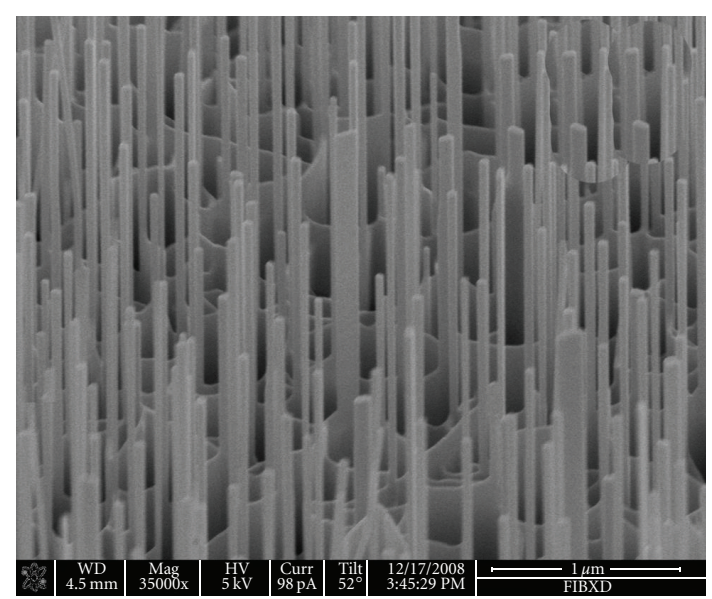

(a)

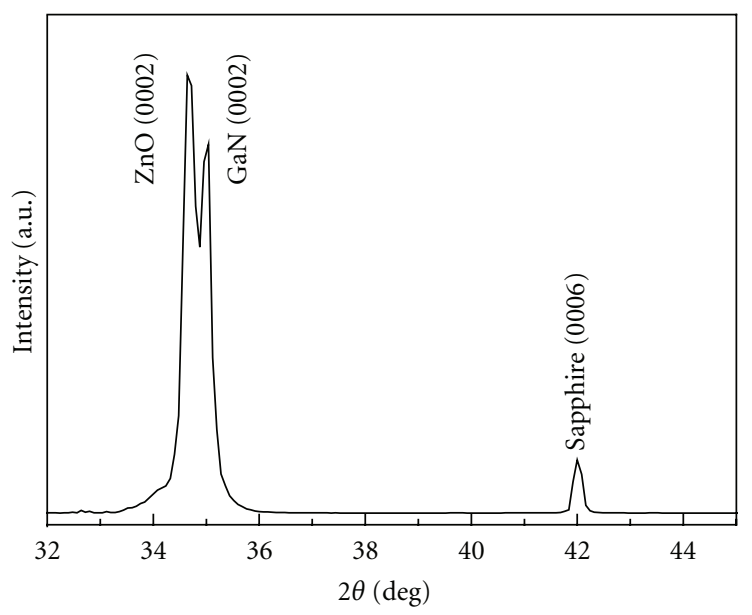

(b)

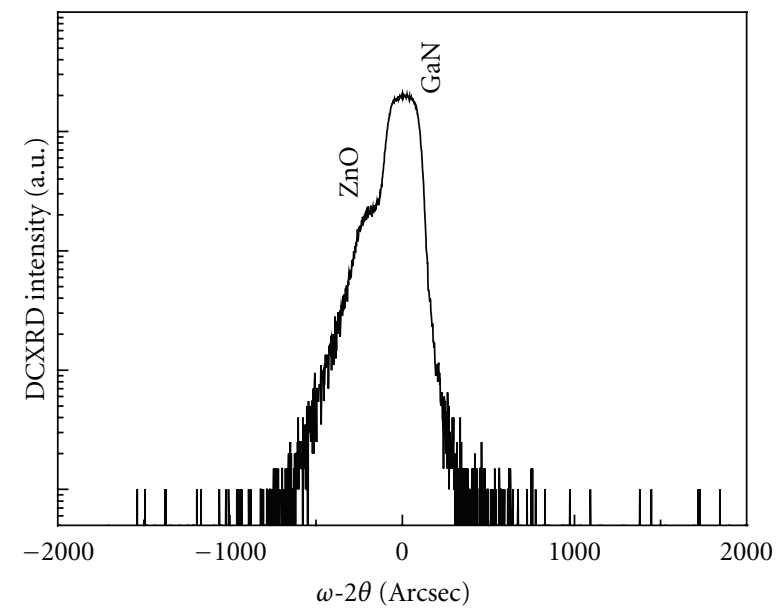

(c)

FIGURE 2: (a) FE-SEM image of as-grown ZnO nanowires on p-GaN film. (b) XRD pattern of as-grown ZnO nanowires. (c) XRD rocking curve of fabricated $\mathrm{n}-\mathrm{ZnO}$ nanowire/p-GaN heterojunction structure.

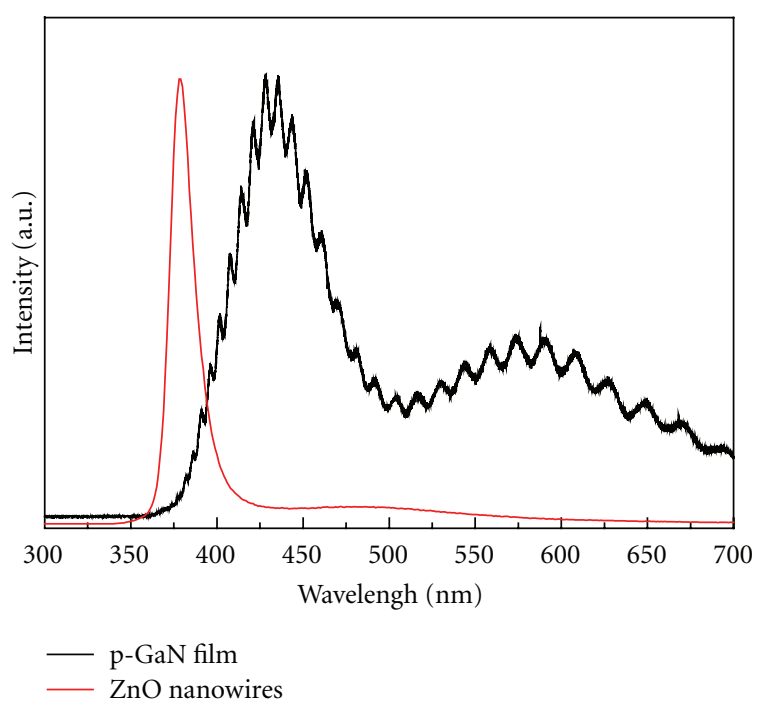

Figure 3: Room temperature PL spectra of as-grown $\mathrm{p}-\mathrm{GaN}$ film and $\mathrm{ZnO}$ nanowires. the heterostructure LED under DC current injection is strong enough to be seen by the naked eye.

\section{Conclusion}

In conclusion, we fabricated the $\mathrm{ZnO} \mathrm{NW} / \mathrm{p}-\mathrm{GaN}$ heterostructure by thermal chemical vapor deposition using a quartz tube furnace and packaged an LED with ITO/glass by a simple process. The photoluminescence spectrum of the pGaN film exhibited broad bands at 432 and $583 \mathrm{~nm}$; these bands are attributed to near-band edge emission by $\mathrm{ZnO}$ with a wide bandgap. The current-voltage characteristics of the fabricated diode indicated that the turn-on voltage was large (approximately $5.5 \mathrm{~V}$ ), which may indicate that the thermal chemical vapor deposition procedure produces a high density of defects at the interface. The room temperature EL emission peak at $425 \mathrm{~nm}$ was attributed to the recombination of electrons and holes in $\mathrm{ZnO}$, causing an unexpected defect to occur in $\mathrm{ZnO}$ or at the interface between $\mathrm{ZnO}$ and $\mathrm{GaN}$. Furthermore, there has been the 


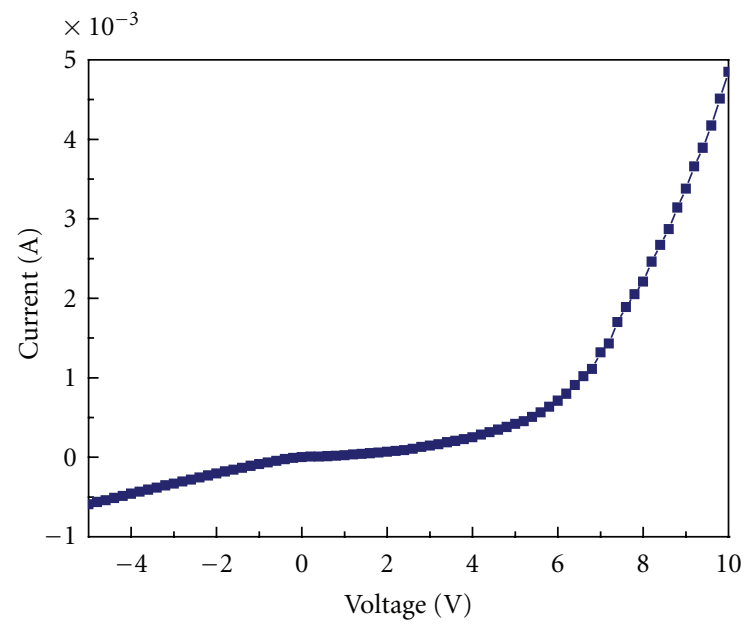

Figure 4: Current-voltage characteristics of fabricated $\mathrm{n}-\mathrm{ZnO}$ nanowire/p-GaN heterojunction LED.

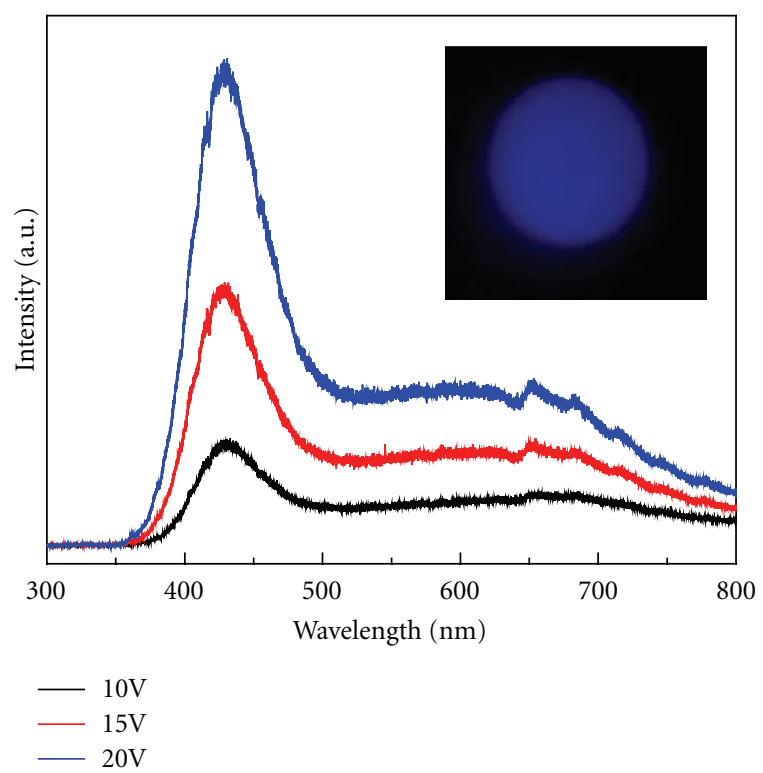

FIGURE 5: EL spectrum of fabricated $\mathrm{n}-\mathrm{ZnO}$ nanowire/p-GaN heterojunction LED.

yellow band in the EL spectrum; it is attributed to the deep defect level in the heterojunction.

\section{Acknowledgments}

This work was supported by the National Science Council under contract numbers NSC 95-2221-E-006-314 and NSC 95-2221-E-006-357-MY3. This work was also supported in part by the Center for Frontier Materials and Micro/Nano Science and Technology, the National Cheng Kung University, Taiwan (D97-2700). This work was also supported in part by the Advanced Optoelectronic Technology Center, the National Cheng Kung University, under projects from the Ministry of Education.

\section{References}

[1] J. Chen, Y. Zhang, B. J. Skromme, K. Akimoto, and S. J. Pachuta, "Properties of the shallow O-related acceptor level in ZnSe," Journal of Applied Physics, vol. 78, no. 8, pp. 5109-5119, 1995.

[2] J. T. Yan, C. H. Chen, S. F. Yen, and C. T. Lee, "Ultraviolet $\mathrm{ZnO}$ nanorod/P-GaN-heterostructured light-emitting diodes," IEEE Photonics Technology Letters, vol. 22, no. 3, Article ID 5342485, pp. 146-148, 2010.

[3] Y. He, J. A. Wang, X. B. Chen, W. F. Zhang, X. Y. Zeng, and Q. W. Gu, "Blue electroluminescence nanodevice prototype based on vertical $\mathrm{ZnO}$ nanowire/polymer film on silicon substrate," Journal of Nanoparticle Research, vol. 12, no. 1, pp. 169-176, 2010.

[4] J. B. K. Law and J. T. L. Thong, "Simple fabrication of a $\mathrm{ZnO}$ nanowire photodetector with a fast photoresponse time," Applied Physics Letters, vol. 88, no. 13, Article ID 133114, 3 pages, 2006.

[5] M. C. Jeong, B. Y. Oh, M. H. Ham, S. W. Lee, and J. M. Myoung, "ZnO-nanowire-inserted $\mathrm{GaN} / \mathrm{ZnO}$ heterojunction light-emitting diodes," Small, vol. 3, no. 4, pp. 568-572, 2007.

[6] J. D. Ye, S. L. Gu, S. M. Zhu et al., "Electroluminescent and transport mechanisms of $\mathrm{n}-\mathrm{ZnO} / \mathrm{p}-\mathrm{Si}$ heterojunctions," Applied Physics Letters, vol. 88, no. 18, Article ID 182112, 3 pages, 2006.

[7] A. C. Mofor, A. Bakin, U. Chejarla et al., "Fabrication of $\mathrm{ZnO}$ nanorod-based $\mathrm{p}-\mathrm{n}$ heterojunction on SiC substrate," Superlattices and Microstructures, vol. 42, no. 1-6, pp. 415420, 2007.

[8] W. I. Park and G. C. Yi, "Electroluminescence in n-ZnO Nanorod Arrays Vertically Grown on p-GaN," Advanced Materials, vol. 16, no. 1, pp. 87-90, 2004.

[9] S. J. An, J. H. Chae, G. C. Yi, and G. H. Park, "Enhanced light output of GaN-based light-emitting diodes with $\mathrm{ZnO}$ nanorod arrays," Applied Physics Letters, vol. 92, no. 12, Article ID 121108, 3 pages, 2008.

[10] C. G. Van de Walle and J. Neugebauer, "Universal alignment of hydrogen levels in semiconductors, insulators and solutions," Nature, vol. 423, no. 6940, pp. 626-628, 2003.

[11] O. Lupan, T. Pauporté, and B. Viana, "Low-voltage UVelectroluminescence from $\mathrm{ZnO}$-Nanowire array/p-CaN lightemitting diodes," Advanced Materials, vol. 22, no. 30, pp. 3298-3302, 2010.

[12] X. M. Zhang, M. Y. Lu, Y. Zhang, L. J. Chen, and Z. L. Wang, "Fabrication of a high-brightness blue-light-emitting diode using a ZnO-Nanowire array grown on p-GaN thin film," Advanced Materials, vol. 21, no. 27, pp. 2767-2770, 2009.

[13] M. C. Jeong, B. Y. Oh, M. H. Ham, and J. M. Myoung, "Electroluminescence from $\mathrm{ZnO}$ nanowires in $\mathrm{n}-\mathrm{ZnO}$ film $/ \mathrm{ZnO}$ nanowire array/ $\mathrm{p}-\mathrm{GaN}$ film heterojunction light-emitting diodes," Applied Physics Letters, vol. 88, no. 20, Article ID 202105, 3 pages, 2006 . 

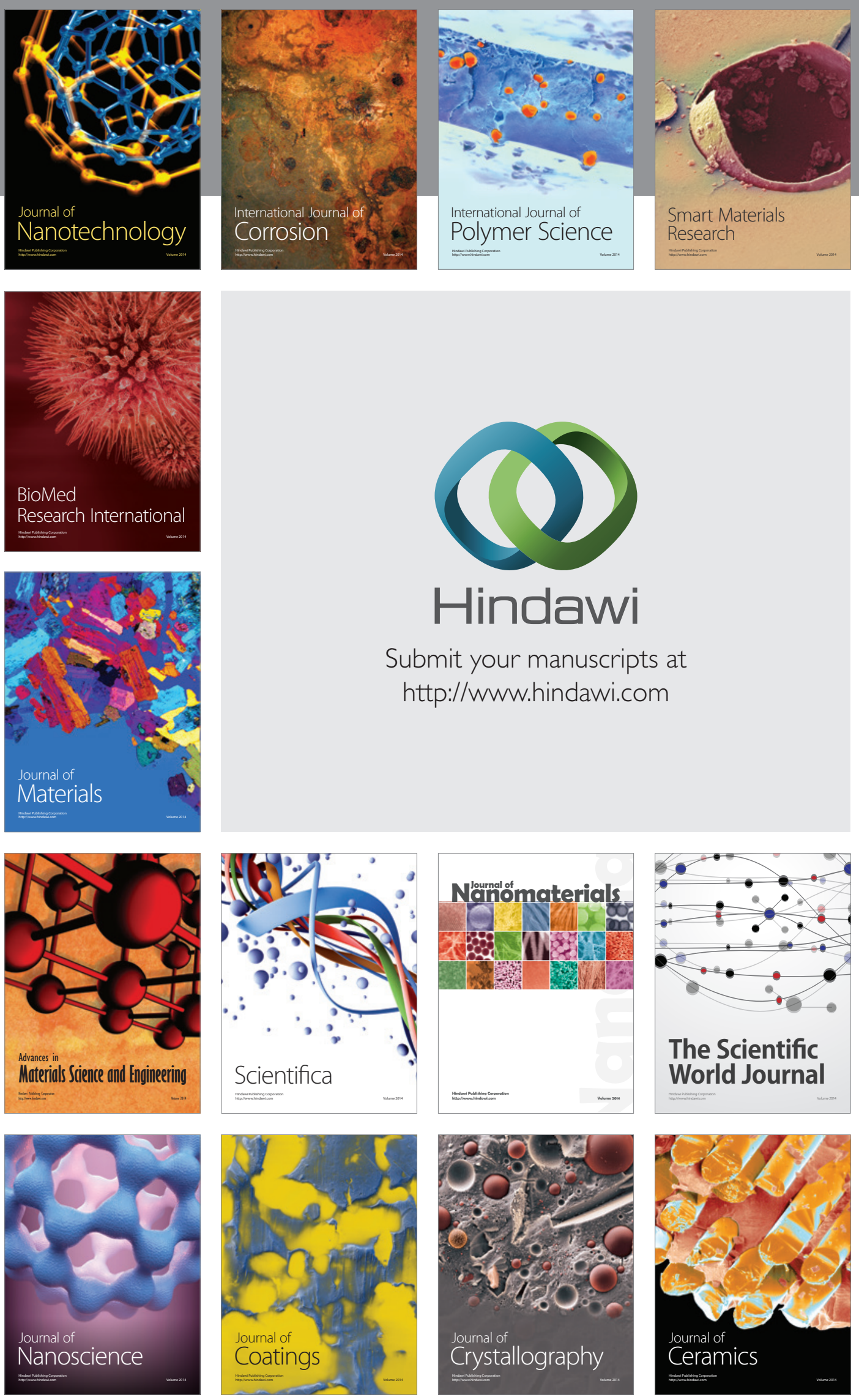

The Scientific World Journal

Submit your manuscripts at

http://www.hindawi.com

\section{World Journal}

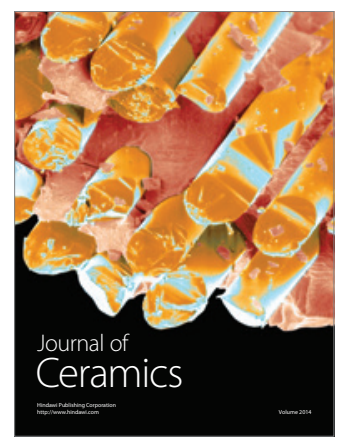

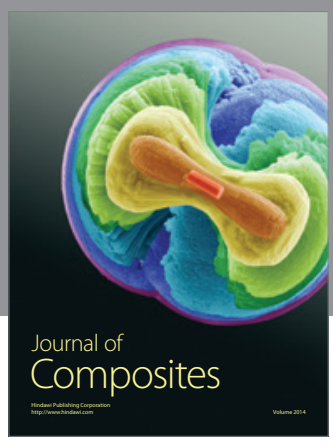
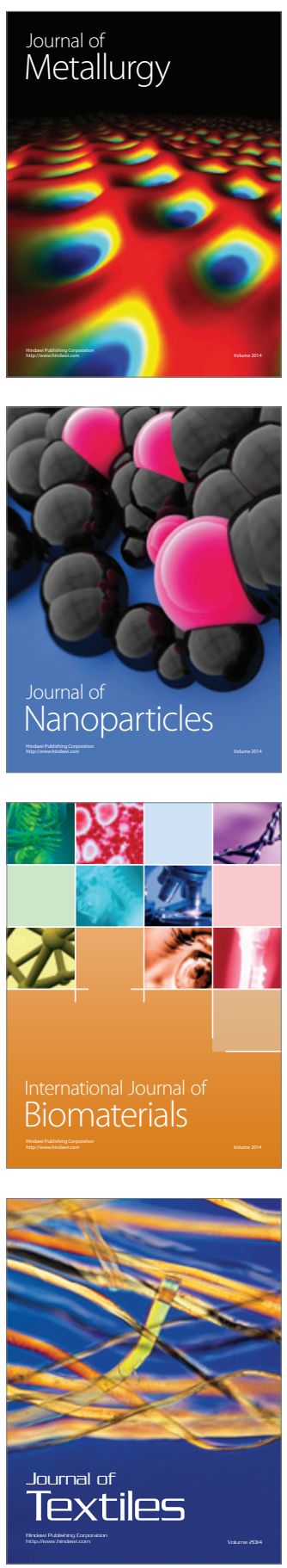